\title{
Poder e autoridade de fundar um mosteiro. A dotação de Santa Clara de Vila do Conde
}

Marisa Costa

RESUMEN. Este artículo se dedica a los orígenes del monasterio de Santa Clara de Vila do Conde, en la segunda década del siglo XIV, por iniciativa de un matrimonio de la alta nobleza portuguesa. Para ello, se ha tenido en consideración la identidad de sus fundadores, en especial del noble, primogénito natural del rey D. Dinis, al igual que el contexto político en el que ocurrió su emprendimiento, sin olvidar, por supuesto, la espiritualidad propia de la época y las prácticas religiosas plasmadas en la historia del arte.

Palabras clave: Monasterio de Santa Clara de Vila do Conde; mecenazgo laico; reinado de D. Dinis; historia política de Portugal.

ABSTRACT. This article analyses the origins of the monastery dedicated to Saint Claire, in Vila do Conde, founded in the second decade of the $14^{\text {th }}$ century, by a couple belonging to the Portuguese high nobility. It was thus considered the identity of the founders, especially the nobleman, natural first born son of King Denis, as well as the political context in which the initiative occurred and, of course, the characteristic spirituality of the time and the religious habits reflected in the history of art.

Key words: Monastery of Saint Claire of Vila do Conde; lay patronage; King Denis' time; Portuguese political history.

Durante o primeiro semestre de 2002, elaborei uma comunicação ${ }^{2}$ dedicada à arquitectura da igreja do extinto mosteiro de Santa Clara de Vila do Conde, localidade situada no norte de Portugal, nas proximidades da cidade do Porto. $\mathrm{Na}$ sequência de outros trabalhos que tenho

\footnotetext{
${ }^{1}$ Aluna do Curso de Mestrado em História da Idade Média, na Faculdade de Letras da Universidade de Coimbra.

${ }^{2}$ Esse trabalho, com o título Viagem por formas e espaços do Gótico: a igreja de Santa Clara de Vila do Conde, foi divulgado no I Congresso de História Medieval, promovido pelo Instituto Superior do Vouga e pela Universidade Portucalense, no âmbito da VI Viagem Medieval em Terras de Santa Maria, em Vila da Feira (Junho de 2002).
}

desenvolvido em torno da fundação desse edifício gótico, verifiquei, então, que estava perante um bom exemplo de uma manifestação de poder e autoridade por parte de alguém que detinha essas premissas e que, por vários motivos, desejara demonstrá-las claramente com a iniciativa da criação de uma casa monástica. Tendo em mente o tema principal do entretanto anunciado 10th International Medieval Congress, subordinado ao tópico «Power and Authority», decidi, assim, aproveitar a oportunidade propiciada pela realização desse prestigiado evento e apresentar um contributo que permitisse dar a conhecer um conjunto de interessantes episódios 
verificados numa época relevante da história portuguesa ${ }^{3}$.

De facto, no sentido da elucidação do respectivo contexto histórico, mergulhar nas origens do referido monumento implicava não apenas mencionar determinados vectores do processo de implantação e expansão das Ordens Mendicantes em território nacional, mas revelava-se igualmente essencial aflorar o ambiente político vivido no início do século XIV, período em que a sua instituição ocorreu. Não fosse "um mosteiro (...) uma sociedade em miniatura, que (...) se deve enquadrar na problemática mais vasta de um todo político-institucional, sócioeconómico e ideológico-cultural de um reino" $^{4}$. Por conseguinte, partindo da abordagem da criação de um cenóbio de Clarissas em Vila do Conde, mediante a análise da sua carta de dotação, redigida em 1318 pelos respectivos fundadores -e cujo teor só seria conhecido por um traslado datado de 10 de Agosto de $1437^{5}$-,

3 O presente estudo resulta, assim, dessa comunicação -intitulada The authority of founding a monastery by the power of a nobleman. The endowment of Santa Clara of Vila do Conde (1318) - apresentada no 10th International Medieval Congress, organizado pela Universidade de Leeds (Inglaterra), em Julho de 2003. Para a minha participação, contei com uma bolsa do International Medieval Congress Bursaries Committee, pelo que gostaria de expressar publicamente o meu agradecimento. Do mesmo modo, gostaria de agradecer à Carla D. Rodrigues, pela sua colaboração na tradução do texto para inglês, e à Filomena Andrade, pela sua disponibilidade e ajuda.

${ }^{4}$ M. H. da C. COelho e R. C. MARTins, "O monaquismo feminino cisterciense e a nobreza medieval portuguesa (séculos XIII-XIV)", Theologica, II $^{\underline{a}}$ Série, Vol. XXVIII, Fasc. 2, Braga, p. 496.

${ }^{5}$ Ignora-se, hoje, qualquer notícia quer sobre o instrumento original, quer sobre as circunstâncias e a altura exacta do seu desaparecimento. A referência mais antiga que se conhece data de meados do século XVII, indicando que a carta era chamada pelas freiras de "Testamento dos Senhores", segundo Frei M. da ESPERANÇA, História Seráfica da Ordem dos Frades Menores de S. Francisco na Província de Portugal, Segunda Parte, Lisboa, 1666, p. 166. Pelas suas propus-me empreender uma perscrutação do tema numa perspectiva mais abrangente, sem pretender, contudo, desviar-me do ponto fulcral que me motivava a participar na iniciativa da Universidade de Leeds, respondendo, desse modo, ao pertinente repto lançado pelos Organizadores do congresso.

O mosteiro de Santa Clara de Vila do Conde foi fundado por D. Afonso Sanches e sua mulher, D. Teresa Martins, na segunda década de Trezentos. De acordo com os cronistas da Ordem de São Francisco em Portugal, que escreveram nos séculos XVII

palavras e pelos excertos contidos nesse relato, poderse-á inferir que o cronista consultou um original da carta de dotação guardado no próprio mosteiro. Entretanto, sabe-se que, em 1437, um descendente dos fundadores, D. Fernando de Meneses, solicitara ao rei D. Duarte a confirmação do manuscrito, para o que se transcreveria o seu teor no livro de registos da chancelaria régia, sendo depois copiado para o $2^{\mathbf{o}}$ Livro de Além-Douro. Sem se perceber bem o motivo, esta última versão parece ter passado a constituir a fonte de informação de todos aqueles que se dedicaram ao assunto, chegando, até, a estar na base da primeira publicação integral da carta, em 1672, por F. BRANDÃO, Monarquia Lusitana, Parte VI, [2 $2^{\underline{a}}$ ed.], introdução de A. da Silva Rego, Lisboa, 1980, pp. 563571. O mesmo se verificou na segunda edição da transcrição, ocorrida já na primeira metade de Setecentos, em A. C. de SoUSA, Provas da História Genealógica da Casa Real Portuguesa, T. I, Ls. I e II, [2 $2^{\underline{a}}$ ed.], edição revista por M. Lopes de Almeida e César Pegado, Coimbra, 1946, pp. 154-165. Posteriormente, em 1943, os estudiosos puderam contar com uma terceira publicação do documento, ainda que reproduzindo as anteriores, inserida na compilação $O$ Cartulário do Mosteiro de Santa Clara de Vila do Conde, [2 $2^{-}$ ed.], edição de Carlos da Silva Tarouca, sep. de "Arqueologia e História», 8 $8^{\text {a }}$ Série, Vol. IV, Lisboa, 1947, Doc. XXIX, pp. 78-89 (acerca desta obra, veja-se o artigo de M. COSTA, "Sobre o «livro dos pergaminhos» ou o «cartulário» do mosteiro de Santa Clara de Vila do Conde", Estudos em homenagem ao Professor Doutor José Marques, Porto, 2004 -no prelo-). Mais recentemente, veio a lume a fonte do traslado de 1437, em Chancelarias portuguesas. D. Duarte, Vol. I, T. 2, organização de João José Alves Dias, Lisboa, 1998, [838], pp. 130-141. Por se tratar da versão mais antiga, optei por utilizá-la neste trabalho -doravante, referida apenas como Chancelarias portuguesas-. 
e $\mathrm{XVIII}^{6}$, durante três noites seguidas do ano de 1314 o casal teria sonhado com uma escada envolta em fumo odorífero que partia do local onde eles se encontravam -o castelo residencial sobranceiro ao rio $\mathrm{Ave}^{7}$ e que tocava o céu, dando passagem para a corte celestial. Ser-lhes-ia, então, revelado que essa escada constituía a prefiguração de um lugar sagrado, assim como o fumo se traduzia em orações que dali surgiriam. Esse fenómeno de índole sobrenatural seria, assim, interpretado por ambos como um sinal de Deus, no sentido de aí criarem um ascetério. Como o senhorio da vila pertencia a D. Teresa Martins por herança ${ }^{8}$, os esposos, tornados os donatários de Vila do Conde, gozavam da riqueza e dos privilégios do seu domínio e respectivas jurisdições, podendo decidir-se pela construção de uma casa monástica.

Assim sendo, da vontade se passou à acção e, em pouco tempo, se materializou o cenóbio vilacondense de Santa Clara. Com efeito, a 15 de Março de 1318 o papa João XXII expediu a bula Ordinem Sanctae Clarae, estabelecendo a regra urbanista como a

\footnotetext{
${ }^{6}$ Fr. M. da ESPERANÇA, ob. cit., pp. 165-167; e Fr. F. da SOLEDADE, Memoria dos Infantes D. Affonço Sanches, e Dona Thereja Martins. Fundadores do Real Mosteiro de Santa Clara de Villa do Conde, Lisboa, 1726, pp. 48-51.

7 Tratava-se de "hum Castelo antigo sobre hüa eminencia, que senhorea o rio, \& pela parte da terra, cujo presidio era, com muito pouco trabalho se podia defender" (Fr. Manuel da Esperança, ob. cit., p. 165). Aparentemente, esse "velho e derrocado castello, que era conhecido pelo nome de castro, e que se demoliu no século XIV para se edificar no seu lugar o mosteiro das freiras de Santa Clara" (I. de V. BARBOSA, As cidades e villas da monarchia portuguesa que teem brasão $d^{\prime}$ armas, Vol. III, Lisboa, 1862, p. 148), terá existido, correspondendo, pois, ao local onde se situava o paço, conforme reiterou J. A. FERREIRA, "Villa do Conde. Notas historicas", O Archeologo Português, Vol. XI, N..s 1-4, Lisboa, Jan.-Abr. 1906, p. 264.

${ }^{8}$ Sobre as origens do senhorio de Vila do Conde, vejam-se idem, Villa do Conde e seu alfoz. Origens e monumentos, Porto, 1923, pp. 11-15; e, por mais recente, J. P. Neves, Vila do Conde, Vila do Conde, 1987, pp. 924.
}

norma a professar no mosteiro ${ }^{9}$. Nesse mesmo ano de 1318, mas a 7 de Maio, os fundadores mandaram lavrar um extenso documento dotando o novo convento, cujo edifício plausivelmente já então existia, porquanto no escatocolo desse acto se indicava que a sua redacção ocorrera dentro do espaço monástico ${ }^{10}$. Em virtude da escassez de fontes conhecidas que facultem informações relativas ao processo fundacional $^{11}$, essa carta de dotação, preciosa por esse e por outros motivos, constitui a única referência documental a aspectos relacionados com a regulamentação da vida espiritual e material da nova comunidade, como sejam a sua natureza religiosa e respectivo comportamento a seguir ${ }^{12}$, a gestão do

9 J. A. FERREIRA, "Villa do Conde. Notas historicas", p. 264. Igualmente referido por Fr. M. da ESPERANÇA, ob. cit., p. 170. Sobre as Regras seguidas pelas comunidades clarissas, consultem-se M. M. S. N. LalandA, "Clarissas (Ordem de Santa Clara)", Dicionário de história religiosa de Portugal, [Vol. I], direcção de Carlos Moreira de Azevedo, Lisboa, 2000, p. 353; e M.F. ANDRADE, «O processo fundacional dos conventos de clarissas no Portugal Medievo», III Congreso Internacional del Monacato femenino en España, Portugal y América, León 2004 (no prelo).

10 "fecta esta carta de hordenaçom no moesteyro de sancta clara de ujlla de conde vij dias de mayo era de mjl iijc Lvj annos" (Chancelarias portuguesas, p. 140). Segundo F. BRANDÃO (ob. cit., p. 269), na citada bula Ordinem Sanctae Clarae, datada, como se disse, de 15 de Março de 1318, o Papa declarava que "ja naquelle Conuento estauão Religiosas (...) dõde se argue que ja do anno antecedente estaua habitado o Conuento".

${ }^{11}$ Uma escassez documental que se estende à vida dos próprios fundadores, dificuldade detectada já no princípio do século XVIII por Fr. F. da SOLEDADE (ob. cit., pp. 1-2), quando, ao empreender a elaboração da sua «memória», constatou que "faltaõ muitas noticias para se inteirar o discurso dos seus progressos. Mostro os que pode alcançar o meu cuidado, se diminutos em comparaçaõ da sua fama, naõ menos limitados à vista das muitas deligencias com que foraõ adquiridos; porém copiozos a respeito da penuria, a que os reduzio o tempo com as variedades, que manifestou nos theatros de quatro seculos".

12 Para além de se terem referido à ordem professada e ao perfil socioeconómico das futuras clarissas -molheres filhas dalgo pobres- (Chancelarias portuguesas, pp. 131-132), os fundadores tiveram a 
património possuído e a disposição dos rendimentos adquiridos ${ }^{13}$, a aplicação desses proventos na manutenção do convento ${ }^{14}$. O empenho dos fundadores chegaria ao pormenor de prescrever regras visando o regime alimentar ${ }^{15}$ e o vestuário ${ }^{16}$ das futuras freiras, ao que parece em conformidade com um costume próprio da época ${ }^{17}$. Contudo, e contrariamente ao que se tem afirmado ${ }^{18}$, a carta não permite estabelecer com precisão nem a sequência desse processo fundacional, onde se inclui a própria construção do edifício, nem a totalidade dos potenciais propósitos subjacentes a tão piedoso cometimento de

preocupação de especificar que não queriam no seu mosteiro "freiras que sayam fora pera pedir esmollas andando pella terra como as ha em outros moesteyros da hordem de sancta clara porque em alguüs moesteyros se segujrom grandes dapnos e algüas per mujtas uezes caaem em grandes deshonrras dos corpos e dapnos das almas nem perque outrossy d entender leixem no serujço de deus e aiam d entender na lazeira se a pedir ounesem" (ibidem, p. 132).

${ }^{13}$ Ibidem, pp. 131-133 e 137-138.

${ }^{14}$ Ibidem, pp. 133-139.

${ }^{15}$ Uma dieta devidamente racionada, composta sobretudo por pão, peixe (fresco ou seco) e vinho, podendo, ainda, conter outros «condutos», conforme se pode ler em ibidem, pp. 133-134.

16 "Outrossy mandamos que de abadesa em cada huü anno por sua vistiaria a cada hüa dona por primeiro dia d outubro seis couodos d arraiz branco e seis uaras de sarja delgada fecta da terra pera sayas e vínte uaras de pano do que fazem em arouca pera aujto e manto" (ibidem, p. 134).

${ }^{17}$ Com efeito, a partir da segunda metade do século XIII assistiu-se ao aparecimento de numerosos regulamentos, amiúde minuciosos, abrangendo os mais diversos âmbitos, como este contemplando o quotidiano de uma comunidade religiosa. Essa prática constituía um reflexo da "propensão comum para racionalizar a vida humana", citando J. MATTOSO, História de Portugal. A monarquia feudal (1096-1480), Segundo Volume, coordenação de idem, Lisboa, 1993, p. 259.

18 Afirmações como as de J. MARQues ("Os Franciscanos no norte de Portugal nos finais da Idade Média", Boletim do Arquivo Distrital do Porto, Vol. I, Porto, 1982, pp. 158 e 160), para quem são bem conhecidos os primórdios da fundação vilacondense, graças à carta, e as circunstâncias da sua instituição. erigir um mosteiro ${ }^{19}$, empreendimento que, como se sabe, se revelava bastante arrojado, por oneroso e amiúde demorado ${ }^{20}$.

Naturalmente, a explicação sobrenatural veiculada pelos mencionados relatos cronísticos não satisfaz qualquer historiador mais atento ao acontecimento. $\mathrm{Na}$ realidade, nenhum dos autores contemporâneos que, com maior ou menor profundidade, se têm dedicado à história do mosteiro de Santa Clara de Vila do Conde se mostrou esclarecido com a alegação dos cronistas, mesmo aqueles mais crentes $^{21}$. Isso não significa, porém, que se deva pôr em causa a profunda religiosidade dos fundadores, seguramente um dos factores inerentes à sua iniciativa. A confirmar o verdadeiro sentimento religioso vivido na época, de preferência direccionado para a mensagem mendicante, em especial a franciscana, são abundantes as passagens -ain-da que eventualmente

19 Assim, as motivações enunciadas na carta de dotação ou «ordenação»-segundo a terminologia dos próprios autores- cingem-se à vertente religiosa da iniciativa- Leia-se Chancelarias portuguesas, pp. 130132).

${ }^{20}$ Sobre a questão, veja-se, por exemplo, a obra póstuma de C. A. F. de AlmeIDA, História da arte em Portugal. O Românico, Lisboa, 2001, em especial o capítulo dedicado à arquitectura. A esse assunto se referiu também A. M. S. A. RODRIGUES, "Patrimónios, direitos e rendimentos eclesiásticos", História religiosa de Portugal, Vol. I, direcção de Carlos Moreira Azevedo, Lisboa, 2000, p. 274.

${ }^{21} \mathrm{Na}$ verdade, essa insatisfação com as motivações sobrenaturais remontará, aparentemente, à segunda metade do século XVII, com a publicação, em 1672, do segundo volume da obra de F. BRANDÃO (ob. cit., p. 269), onde já se pode detectar uma proposta de outro género de justificações, embora, claro, em contexto devocional. Influenciado por essa proposta, J. A. FERREIRA ("Villa do Conde. Notas historicas", p. 264) o célebre monsenhor que dedicou uma parte da sua vida à história vilacondense e bracarense- consideraria também, e a par dos argumentos mais piedosos, a possibilidade de a iniciativa do casal fundador, conquanto movido pela devoção, ter estado relacionada com uma decisão semelhante -tida como anterior- da rainha D. Isabel de Aragão. 
tipificadas- da carta de dotação que remetem para essa motivação da fundação ${ }^{22}$. Nesse sentido, a resolução do nobre casal consistiu numa iniciativa em nada inaudita ou mesmo invulgar, conforme se sabe ${ }^{23}$ e se exemplificará mais adiante.

No entanto, o empreendimento de D. Afonso Sanches e de sua mulher denota demasiadas coincidências com uma série de acontecimentos ocorridos antes, durante e depois da concretização do seu monumental projecto, balizada, assim, entre 1314 e 1318. Acontecimentos esses que gravitaram nas esferas do político, do social e do mental, e em cujos âmbitos não se poderá deixar de integrar a instituição do cenóbio vilacondense. Para esta questão dos verdadeiros -ou, melhor dizendo, principais- factores intrínsecos à decisão do ilustre casal é fundamental ter em consideração o facto de D. Afonso Sanches ser filho ilegítimo de D. Dinis, soberano que

\footnotetext{
22 Como no início da carta, "Porem nos $<$ dom $>$ Afonso sanchez d albuquerque (...) E dona tareija martjnz sua molher (...) parando mentes ao mujto bem e mujta mercee e mujta honrra que em este mundo recebemos de deus quanto the nos serujr nem conhecer nom poderiamos, auendo uontade e deseío de lhe conhecer algüa parte da mercee que nos ha fecta $E$ que del atendemos specialmente despois de nossas mortes <Receber> porque somos certos que auemos de hir a seu poder hu o bem he perdurauel e nom pasa de cada dia em uaão como o deste mundo catamos camjnho perque algü̈ serujço recebese deus por nosso hordenamento E Porem aa honrra sua que he padre e filho e spiritu sancto E a honrra e louuor da ujrgem gloriosa sancta maria sua madre $E$ de toda a corte celestial $E$ da bem auenturada sancta clara" (Chancelarias portuguesas, pp. 130-131). Ou, mais adiante, "porque entendemos que se segujria ende mujto bem por mujtas razoões a hüa serujr a deus e saluansam per hi serujndo o E a outra por rogarem a deus por nos que nos faça mercee $E$ que el que nos deu conhecimento de bem nos leixe acabar bem em nossos dias a seu serujço perque mereçamos d auer saluacam das almas" (Chancelarias portuguesas, pp. 131-132).

${ }^{23}$ Revela-se elucidativo o texto de M. de L. RosA, "A religião no século: vivências e devoções dos leigos", História religiosa de Portugal, pp. 452-460.
}

governou Portugal entre 1279 e $1325^{24}$. Não se tratava do único bastardo régio ${ }^{25}$, mas, talvez por ser o primogénito ${ }^{26}$, granjeou claramente a predilecção do pai.

Com efeito, a partir dos estudos até hoje realizados sobre o reinado dionisino ${ }^{27}$, bem como da análise da reduzida documentação conhecida relacionada com o mosteiro nessa fase inicial $^{28}$, é possível asseverar que o monarca não só "trazia consigo [o filho] que ele muito amava"29, como

${ }^{24}$ Para uma visão geral do seu reinado, consultese uma das sínteses mais recentes, de $\mathrm{M}$. H. da $\mathrm{C}$. COElHo, "O reino de Portugal ao tempo de D. Dinis", Imagen de la Reina Santa. Santa Isabel, infanta de Aragón y reina de Portugal, Vol. II (Estudos), Saragoça, 1999, pp. 50-83.

${ }^{25}$ Sobre a descendência do monarca, sugere-se a consulta do estudo mais actualizado, de J. A. de S. M. PIZARRO, Linhagens medievais portuguesas. Genealogias e estratégias (1279-1325), Vol. I, Porto, 1999, pp. 184-200.

${ }^{26}$ Foi fruto de uma relação de D. Dinis com Aldonça Rodrigues de Telha (Livro de Linhagens do Conde D. Pedro. Portugaliae Monumenta Historica, Nova Série, Vol. II/1, edição crítica de José Mattoso, Lisboa, 1980, 57J4, pp. 93-94), uma "dama pertencente à nobreza secundária do Minho e filha de Roy Gomes de Telha, antigo fidalgo da corte de D. Afonso III" (M. BARBIERI, "Afonso Sanchez", Dicionário da literatura medieval galega e portuguesa, organização e coordenação de Giulia Lanciani e Giuseppe Tavani, Lisboa, 1993, p. 22). D. Afonso Sanches nasceu antes do primeiro filho legítimo -a infanta D. Constança- do rei e da infanta aragonesa D. Isabel (na sequência do matrimónio em 1282). Sobre a questão da primogenitura, veja-se $M$. COSTA, «Entre afficção ea realidade. O modelo historiográfico de D. Alonso Sanches», Modelo. V Colóquio da Secção Portuguesa da Associação Hispânica de Literatura Medieval, Porto, 2004 (no prelo).

${ }^{27}$ Já para uma leitura mais aprofundada, sugere-se como ponto de partida a sinopse de A. L. de C. HomeM, "A dinâmica dionisina", em M. H. da C. Coelho e A. L. de C. Homem (Coord.), Portugal em definição de fronteiras. Do Condado Portucalense à crise do século XIV. Nova história de Portugal, Vol. III, direcção de Joel Serrão e A. H. de Oliveira Marques, Lisboa, 1996, pp. 144-163.

${ }^{28}$ Coligida em O Cartulário do Mosteiro de Santa Clara de Vila do Conde, Docs. VII a XVI, pp. 44-59.

29 Citando uma das fontes narrativas mais próximas da época -ainda do século XIV-, Livro de Linhagens do Conde D. Pedro. Portugaliae Monumenta Historica, 21G14, p. 238. Segundo J. A. FERREIRA (Os 
dera bastas provas da sua estima, traduzidas na atribuição de numerosas doações e abundante numerário, além das manifestações de favoritismo e da concessão de um importante cargo curial. A par disso, desde cedo que o predilecto se movimentava pela corte do progenitor, tendo sido, até, educado nesse ambiente, juntamente com os outros irmãos, naturais e legítimos. Uma educação e um ambiente que o converteriam num exímio mestre da «arte de trovar», à imagem, pois, do próprio D. Dinis. Causa ou consequência, o seu talento poético assegurar-lhe-ia igualmente uma posição política assaz vantajosa $^{30}$. Por ser filho de rei e estar casado com uma mulher de elevada estirpe e grande nobreza, como era D. Teresa Martins ${ }^{31}$, D. Afonso Sanches tornara-se, então, um homem muito rico e "todopoderoso" $^{\prime 32}$.

No primeiro conjunto de tais demonstrações de afecto, as doações régias -tanto de pachoados como de terrasverificaram-se em duas vertentes. Assim, destinaram-se, por um lado, à pessoa do filho, documentalmente iniciadas em $1291^{33}$

-

túmulos de Santa Clara de Villa do Conde, Porto, 1925, p. 13), "D. Denis amava loucamente D. Affonso Sanches".

${ }^{30}$ Nas palavras de M. BARBIERI (ob. cit., p. 22), para quem a produção trovadoresca de D. Afonso Sanches apresenta "características das mais singulares" no contexto da lírica galaico-portuguesa.

31 Desconhece-se a data exacta do matrimónio, embora as conjecturas apontem para um período balizado entre finais de 1304 e Fevereiro de 1306 (J. A. de S. M. PIZARRO, ob. cit., p. 191, n. 154) ou 4 de Agosto do mesmo ano de 1306 (M. J. BARROCA, Epigrafia medieval portuguesa (862- 1422), Vol. II, T. 2, Lisboa, 2000, p. 1304). Sobre D. Teresa Martins e sua ascendência, veja-se A. B. FREIRE, Brasões da Sala de Sintra, Vol. I, [3 $3^{\mathbf{a}}$ ed.], apresentação e apêndices de Luís Bivar Guerra, Lisboa, 1973, pp. 106-108.

${ }^{32} \mathrm{Na}$ expressão de J. A. de S. M. PiZARRO, "D. Dinis e a nobreza nos finais do século XIII", Revista da Faculdade de Letras. História, 2a Série, Vol. 10, Porto, 1993, p. 99.

33 Segundo dados divulgados por A. R. de OliveIRA, Depois do espectáculo trovadoresco. A estrutura -ainda muito jovem ${ }^{34}-$, contribuindo, desse modo, para a formação do seu extenso património $^{35}$, e, por outro lado, ao cenóbio vilacondense. Nesse sentido, os documentos remanescentes denunciam D. Dinis como o primeiro a fazer doações ao ascetério, datando a mais antiga de 9 de Abril de $1318^{36}$. Marcando sempre presença no decurso do processo fundacional, $\mathrm{o}$ monarca chegaria mesmo a declarar-se protector do cenóbio entre 1318 e 1319, ao confirmar a carta de dotação ${ }^{37}$ e renunciar, por si e pelos seus sucessores, a todos os direitos a usufruir do novo mosteiro de Santa Clara ${ }^{38}$.

Privilégios reais que se juntavam, então, às avultadas benesses outorgadas pelos fundadores, incluindo o senhorio de Vila do Conde e respectivas jurisdições após o falecimento de ambos ${ }^{39}$. Em virtude das determinações da primeira Regra de Santa Clara sobre a posse de bens materiais por parte das comunidades monásticas que a adoptassem, D. Afonso Sanches e D. Teresa Martins tinham solicitado à autoridade papal, na figura do mesmo João

dos cancioneiros peninsulares e as recolhas dos séculos XIII e XIV, Lisboa, 1994, p. 311; e por J. A. de S. M. PIZARRO, Linhagens medievais portuguesas. Genealogias e estratégias (1279-1325), p. 189 , n. 142.

${ }^{34}$ Até ao primeiro quartel do século $X X$, aceitou-se que o nascimento de D. Afonso Sanches ocorrera entre 1279 (J. A. FERREIRA, Os túmulos de Santa Clara de Villa do Conde, p. 11) e 1289 (F. BRANDÃO, ob. cit., Parte V, 1976, fl. 174v), algures na actual província de EntreDouro-e-Minho (Fr. F. da SOLEDADE, ob. cit., pp. 3-4). A historiografia actual tem situado o acontecimento antes de 1289.

${ }^{35}$ Sobre asunto tão saliente, estou a ultimar um trabalho intitulado «Os bens fundiários de D. Alfonso Sanches. Radiografia de um património», com publicação prevista para 2005.

${ }^{36}$ Em O Cartulário do Mosteiro de Santa Clara de Vila do Conde, Doc. XI, pp. 52-53.

${ }^{37}$ Documento datado de 3 de Janeiro de 1319, em ibidem, Doc. XIV, pp. 55-56.

${ }^{38}$ Documento datado de 4 de Janeiro de 1319, em ibidem, Doc. XV, pp. 57-58.

${ }^{39}$ Confira-se em Chancelarias portuguesas, p. 138. 
XXII, a ratificação das constituições que consideravam as propriedades e as rendas necessárias à sobrevivência das freiras de clausura ${ }^{40}$, condição da comunidade vilacondense por vontade expressa na carta de dotação $0^{41}$. Assim sendo, o cenóbio pôde ser provido de um grande número de bens fundiários, direitos e prerrogativas, numa quantidade que em muito ultrapassava o essencial para garantir o sustento das religiosas.

Também outras fundações de conventos consagrados a Santa Clara beneficiaram de apoio financeiro e protecção régia, à semelhança, aliás, de diversas comunidades masculinas de Mendicantes. Na verdade, esse género de iniciativas constituía já uma prática corrente entre os monarcas, que, em alguns casos, chegariam a desempenhar um papel determinante na criação de certas instituições religiosas ${ }^{42}$. No período em questão, refiram-se, inevitavelmente, os nomes de D. Dinis e D. Isabel de Aragão, sua mulher, promotora da (re)fundação da

${ }^{40}$ Licença concedida pela bula Apostolicae Sedis, dada em Avinhão, a 27 de Fevereiro de 1319, conforme indicação de Fr. M. da ESPERANÇA, ob. cit., p. 172. Igualmente referido por J. A. FERREIRA, "Villa do Conde. Notas historicas", p. 265.

41 "E esta doaçam fazemos a este nosso moesteyro sob tal preito e condiçom que víuam hi em este nosso moesteyro pera sempre donas dessa hordem de sancta clara ençarradas sob aquella regra e priujllegios e graças que nos o papa ha dados e outorgados ou der e outorgar daqui em diante pera este nosso moesteyro" (Chancelarias portuguesas, p. 131).

42 Para uma visão de conjunto desses antecedentes, veja-se M. de L. ROSA, ob. cit., pp. 423452. No plano artístico, revela-se de bastante utilidade a leitura de C. A. F. de AlmeIDA, ob. cit., pp. 67-69. Especificamente sobre a actuação no feminino, sugerem-se M. H. da C COELHO e R. C. MARTINS, art. cit., pp. 481-506; e, embora com menos dados pertinentes, M. A. F. MARQUES, "Evolução do monaquismo feminino, até ao século XIII, na região de Entre Douro e Tejo", Estudos sobre a Ordem de Cister em Portugal, Lisboa, 1998, pp. 9-27. casa clarissa em Coimbra ${ }^{43}$. Antes deles, apontem-se o rei D. Afonso III (1248-1279), para a comunidade clarissa de Santarém ${ }^{44}$, e a sua esposa, a rainha D. Beatriz, no fomento das casas franciscanas de Alenquer e Estremoz ${ }^{45}$. Outro soberano que contribuiu para a implantação dos Mendicantes em território português foi D. Sancho II (1223-1245), incentivando a criação das comunidades franciscana de Santarém ${ }^{46}$ e dominicana de Lisboa ${ }^{47}$. Essa protecção da monarquia abrangia com frequência, como também se sabe,

43 Sobre essa (re)fundação, obtenham-se esclarecimentos em F. F. LOPES, "Fundação do Mosteiro de Santa Clara de Coimbra. Problema de Direito medieval", Colectânea de Estudos, 2ª Série, Ano IV, N.o 1, Braga, Maio 1952, pp. 166-192. Para uma ideia global do patrocínio do casal régio no plano monumental, leia-se, como começo, a síntese de F. P. de MACEDO, "Manifestações artísticas", em M. H. da C. CoelHo e A. L. de C. HOMEM (Coord.), ob. cit., pp. 727728; e P. DIAS, A arquitectura gótica portuguesa, Lisboa, 1994, pp. 83-87. Complementem-se, depois, essas informações com os dados documentais facultados para a actuação do monarca, por J. A. de S. M. PIZARRO, "D. Dinis e a nobreza nos finais do século XIII", p. 92.

${ }^{44}$ A primeira iniciativa de uma longa série de fundações régias, de acordo com A. M. MOREIRA, "Breve história das Clarissas em Portugal", Las Clarisas en España y Portugal. Congreso Internacional (Salamanca, 20-25 de septiembre de 1993), T. II/1, Madrid, 1994, pp. 212-213. A propósito da protecção de D. Afonso III aos Franciscanos, consulte-se J. MATTOSO, "O enquadramento social e económico das primeiras fundações franciscanas", Portugal medieval. Novas interpretações, 2 ${ }^{\underline{a}}$ ed., [Lisboa], [1992], pp. 342-343. Para uma perspectiva artística, C. A. F. de Almeida e M. J. BARROCA, História da Arte em Portugal. O Gótico, Lisboa, 2002, pp. 49-50; e F. P. de MACEDO, ob. cit., p. 726.

${ }^{45}$ Mais elementos em P. DIAS, ob. cit., pp. 72 e 8082; C. A. F. de Almeida e M. J. BARROCA, ob. cit., pp. 50-51; e, especificamente sobre a casa de Estremoz, F. P. de MACEDO, ob. cit., p. 726.

${ }^{46}$ Sobre a história do monumento, G. PRADALIÉ, O Convento de São Francisco de Santarém, Santarém, 1992. Para a perspectiva artística, C. A. F. de AlmeIDA e M. J. BARROCA, ob. cit., pp. 48-49; e F. P. de MACEDO, ob. cit., pp. 725-726.

${ }^{47}$ Como ponto de partida, remete-se para H. V. VILAR, "Os frades mendicantes", História religiosa de Portugal, p. 231. 
membros da família real. A título de exemplo, D. Leonor Afonso, filha ilegítima de D. Afonso III, abraçou a Ordem de Santa Clara ingressando na casa escalabitana ${ }^{48}$, impulsionada, como se disse, pelo pai. Décadas antes, duas filhas do rei D. Sancho I (1185-1211), de nome Teresa e Sancha, tinham colaborado no estabelecimento das comunidades franciscana de Montemor-oVelho e dominicana de Coimbra -a primeira infanta-, e franciscana de Alenquer -a segunda infanta- ${ }^{49}$.

Além dos ilustres familiares de reis e rainhas, houve elementos da nobreza portuguesa que, em maior ou menor escala, ficariam na história como devotos piedosos e generosos para com os Mendicantes. De novo, esses nobres mantinham um hábito antigo, porquanto os empreendimentos dessa natureza permitiam-lhes "fixar solidamente, através de monumentos inabaláveis, a marca da sua posição eminente ${ }^{\prime \prime 50}$. De entre as criações destinadas à Ordem de Santa Clara, saliente-se o caso de D. Châmoa Gomes e seu marido, o fidalgo leonês D. Rodrigo Froilaz, fundadores de uma comunidade em EntreAmbos-os-Rios (na região do Porto), em $1256-1257^{51}$. E o caso de D. Mor Dias,

-

${ }^{48}$ Segundo A. M. MOREIRA, ob. cit., p. 213. E onde jaz sepultada desde 1319 (C. A. F. de AlmeidA e M. J. BARROCA, ob. cit., p. 49).

${ }^{49}$ Confira-se em M. de L. ROSA, ob. cit., pp. 454455; e J. MATTOSO, "O enquadramento social e económico das primeiras fundações franciscanas", p. 332. Para a perspectiva artística, F. P. de MACEDO, $o b$. cit., p. 724.

J. MAtTOSO, "O Românico português. Interpretação económica e social", Portugal medieval. Novas interpretações, p. 165. Sobre a "exploração dos laços que envolvem a nobreza e os mosteiros" desde muito cedo, revela-se também de utilidade a leitura de M. H. da C. COELHO e R. C. MARTINS, art. cit., pp. 481506 (citação na pág. 482).

${ }^{51}$ Embora a bula papal que autorizou a fundação date de 18 de Março de 1256, a regra só seria outorgada, também por bula, a 25 de Abril de 1258, de acordo com A. M. MOREIRA, ob. cit., pp. 213-214; e M. promotora da árdua implantação do mosteiro de Clarissas de Coimbra, entre 1283 e $1285^{52}$. A casa feminina de Lisboa, fundada entre 1288 e 1294, ficou a dever-se à iniciativa de quatro nobres senhoras da cidade, com destaque para D. Inês Fernandes, "asturiana de nascimento e viúva de um rico mercador genovês que vivera largos anos" na actual capital ${ }^{53}$. $\mathrm{O}$ outro cenóbio de Clarissas surgido ainda no século XIII, resultado de uma congregação espontânea de leigas devotas ${ }^{54}$, consistiu naquela que é considerada a mais antiga comunidade feminina em Portugal, criada em Lamego, em $1258^{55}$, e transferida para Santarém, no ano seguinte, já com a citada protecção de D. Afonso III.

No pequeno conjunto dos primeiros ascetérios de Clarissas em Portugal, a fundação do mosteiro vilacondense ocorreu, pois, numa fase avançada do

M. S. N. LalANDA, ob. cit., p. 353. Veja-se M.F. ANDRADE, ob. cit. Para J. MARQUES (art. cit., p. 159), a fundação deste mosteiro ocorreu posteriormente a 1258.

${ }^{52}$ Obtenha-se uma ideia geral em A. M. MOREIRA, ob. cit., pp. 214-215; e em M.F. ANDRADE, ob. cit. Para as origens da comunidade conimbricense, veja-se $\mathrm{o}$ estudo de A. P. P. F. SANTOS, A fundação do mosteiro de Santa Clara de Coimbra (Da instituição por D. Mor Dias à intervenção da rainha Santa Isabel), 2 vols., Coimbra, Dissertação de Mestrado em História da Idade Média apresentada à Faculdade de Letras da Universidade de Coimbra, 2000.

${ }^{53}$ A. M. MOREIRA, ob. cit., p. 216. Mais elementos em M.F. ANDRADE, ob. cit.

54 Conforme registou J. MAtTOSO ("O enquadramento social e económico das primeiras fundações franciscanas", p. 344), trata-se do cenóbio de Clarissas cujas origens -mediante o agrupamento de antigas beguinas de Lamego- possuem um "enquadramento sociológico" mais próximo dos mosteiros franciscanos.

55 Apesar da fundação de Entre-Ambos-os-Rios em 1256-1257, a casa lamecense seria a primeira a receber a Regra de Santa Clara, por uma bula datada de 20 de Fevereiro de 1258, de acordo com A. M. MOREIRA, $o b$. cit., pp. 211-213. Questão igualmente explicitada por M. M. S. N. LALANDA, ob. cit., p. 353; e bem documentada por M.F. ANDRADE, ob. cit. 
processo de fixação da rede mendicante, em período que os Frades Menores e Pregadores já tinham conseguido atingir "a normalidade institucional, a inserção pacífica nas estruturas civis e eclesiásticas"56. Apesar de não ser possível abordar aqui o fenómeno mendicante no reino português ${ }^{57}$-análogo ao verificado em outros reinos europeus ${ }^{58}$-, que começou no princípio da centúria de Duzentos, com a implantação das casas franciscanas de Alenquer, Guimarães e Lisboa (1217) ${ }^{59}$, e dominicanas de Santarém (1222) e Coimbra $(1227)^{60}$, convirá alertar para o facto de o estabelecimento das comunidades afectas à Ordem de São Domingos e, sobretudo, à Ordem de São Francisco ter-se diferenciado bastante da fundação dos conventos

56 J. MATTOSO, "O enquadramento social e económico das primeiras fundações franciscanas", p. 339.

57 Sobre a entrada e implantação das Ordens Mendicantes em Portugal, tenha-se como ponto de partida a recente síntese de H. V. VILAR, ob. cit., pp. 228-233. No plano arquitectónico, sugere-se outra síntese, de F. P. de MACEDO, ob. cit., pp. 723-729.

${ }^{58}$ Sobre a realidade mais próxima, a da vizinha Espanha, propõe-se, de entre as numerosas obras consagradas ao tema, a consulta das actas da VI Semana de Estudios Medievales de Nájera, coordenação de José Ignacio de la Iglesia Duarte, Logroño, 1996, onde se pode encontrar uma abundante bibliografia de apoio, reunida por Tomás Sáenz de Haro (pp. 301336). Para a história da Ordem de Santa Clara, vejamse, por exemplo, J. GARcía Oro, "Origenes de las Clarisas en España", Las Clarisas en España y Portugal. Congreso Internacional (Salamanca, 20-25 de septiembre de 1993), pp. 163-182; e, já mais regional, G. CAVERO DOMÍNGUEZ, "Monarquia y nobleza: su contribución a las fundaciones de Clarisas en Castilla y León (siglos XIII-XV)", ibidem, pp. 257-279.

59 De acordo com a cronologia seguida por J. MATTOSO, "O enquadramento social e económico das primeiras fundações franciscanas", pp. 339-340; e por A. M. MOREIRA, "Franciscanos", Dicionário de história religiosa de Portugal, [Vol. II], p. 273. Especificamente sobre a casa franscicana de Guimarães, existem opiniões diferentes, como a de José Marques, art. cit., p. 153.

${ }^{60}$ Seguindo agora as datas apresentadas por R. A. Rolo, "Dominicanos", Dicionário de história religiosa de Portugal, [Vol. II], p. 82. medievais dedicados a Santa Clara, quer na sua cronologia, quer, sobretudo, nos seus propósitos e enquadramentos ${ }^{61}$. Com efeito, as comunidades de Clarissas surgidas a partir da segunda metade do mesmo século XIII situavam-se tanto em meios urbanos como rurais, não reflectindo, nesta segunda paisagem, alterações significativas em relação às casas beneditinas $\mathrm{e}$ cistercienses ${ }^{62}$. Além disso, e como ficou ilustrado, quase todas estiveram intimamente ligadas à protecção da alta nobreza e do círculo régio ${ }^{63}$.

Integrando-se sem hesitações nessa caracterização, a fundação do mosteiro de Vila do Conde apresentou, todavia, algumas excepções, por certo decorrentes da identidade dos seus fundadores e, por extensão, do apadrinhamento da iniciativa por parte do monarca. Assim, acompanhando todo o processo fundacional, como se disse, a sua intervenção, mais ou menos directa, não se quedou pelas generosas doações. A 10 de Janeiro de 1319, uma carta régia -assinada pelo próprio D. Dinis- dispensava o cenóbio vilacondense de algumas leis promulgadas anos antes ${ }^{64}$, mediante as

\footnotetext{
${ }^{61} \mathrm{Na}$ linha de J. MATTOSO, "O enquadramento social e económico das primeiras fundações franciscanas", p. 344.

${ }^{62}$ Idem, ibidem, p. 344. Para uma visão de conjunto do historial das Clarissas em Portugal, sugere-se M. M. S. N. LALANDA, ob. cit., pp. 353-355.

${ }^{63}$ Maior desenvolvimento em M.F. ANDRADE, $o b$. cit. Nesse aspecto, a realidade portuguesa aproxima-se bastante da de outros países. De novo, retenha-se o exemplo da vizinha Espanha, para o que se volta a remeter o leitor para o estudo de G. CAVERO DOMÍNGUEZ (ob. cit., pp. 258-265), circunscrevendo-se a fundações no reino de Castela e Leão; e para o contributo de J. MARTínEZ DE AGUIRRE, «Espiritualidad franciscana y arquitectura gótica: del recelo a la revitalización», VI Semana de Estudios Medievales de Nájera, pp. 111-131, em especial o ponto dedicado ao mecenato das "elites urbanas, nobleza tradicional y familias reales" (pp. 126-131).

${ }^{64}$ Em O Cartulário do Mosteiro de Santa Clara de Vila do Conde, Doc. XVI, pp. 58-59.
} 
quais a Coroa interditara todas as instituições religiosas do reino de comprar e herdar bens de raiz ${ }^{65}$. Naturalmente, pelo seu significado, essa deliberação de 1319 desagradou a alguns membros da família real e, inclusive, da corte, como se verá a seguir. Para além do mosteiro fundado pelo primogénito, seriam poucos os beneficiários de semelhante privilégio. Poucos e devidamente identificados, conforme exemplifica a comunidade cisterciense de Odivelas, em Lisboa. É que S. Dinis de Odivelas fora instituído pelo próprio monarca ainda nos finais de Duzentos, tornando-se depois o seu panteão ${ }^{66}$.

Quanto ao segundo conjunto de favores paternos alcançados por D. Afonso Sanches, o ponto culminante do seu percurso político radicou na elevação ao mais importante cargo curial, a saber, mordomo-mor do reino, plausivelmente em $1312^{67}$. A decisão de D. Dinis nomear aquele filho natural o responsável pela

${ }^{65}$ Sobre essa legislação régia, designada pela historiografia de «leis de desamortização», e que se reveste "de grande originalidade se comparada com as de outros Estados da Europa ocidental", vejam-se, como ponto de partida, A. H. de O. MARQues, "Desamortização. Leis de", Dicionário de história de Portugal, Vol. I, direcção de Joel Serrão, [Lisboa], [1970], pp. 801-802 (citação na pág. 802); e, já mais actualizado, A. M. S. A. RODRIGUES, "Desamortização", Dicionário de história religiosa de Portugal, [Vol. II], pp. 59-60.

66 Como introdução à questão, propõe-se a consulta de H V. VILAR e M. J. V. B. M. da SILVA, "A fundação do mosteiro de Odivelas", Congreso Internacional sobre San Bernardo e o Cister en Galicia e Portugal (Actas), Vol. I, Ourense, 1992, pp. 589-601. Para mais informações, M. I. da S. PINTO, O mosteiro de Odivelas no século XIV. Património e gestão, Lisboa, Dissertação de Mestrado em História Medieval apresentada à Faculdade de Ciências Sociais e Humanas da Universidade Nova de Lisboa, 2001.

${ }^{67}$ Referido por F. BRANDÃO, ob. cit., Parte VI, p. 21; e documentado por J. A. de S. M. PIZARRO, Linhagens medievais portuguesas. Genealogias e estratégias (12791325), p. 190, n. 144. orgânica do governo provocaria, quase infalivelmente, uma forte reacção do príncipe herdeiro. $\mathrm{Na}$ realidade, há já algum tempo que o infante D. Afonso, instigado por um grupo de conselheiros insatisfeitos com a actuação do poder central face ao partido senhorial 68 , contestava certas determinações do progenitor, sobretudo as que denunciavam a predilecção régia por aquele meio-irmão, reforçando-lhe o valimento. Nessas determinações incluía-se, pois, o apoio à fundação do cenóbio vilacondense. Ora, na perspectiva do herdeiro, D. Afonso Sanches começara então a ameaçar a sua ingénita ascensão ao trono ${ }^{69}$. Por esse motivo, o infante não só reclamava contra a atribuição do cargo, como exigia a devolução dos bens, traduzidos quer nas terras quer no dinheiro, que o rei oferecera ao bastardo nos últimos anos.

A rejeição das várias exigências por parte de D. Dinis e a consequente -e crescente- oposição de D. Afonso arrastaram-se por mais algum tempo, agudizando-se os conflitos, que, a médio prazo, extravasariam o círculo familiar e cortesão $^{70}$. Assim sendo, esses e outros episódios resultantes da política interna do

\footnotetext{
${ }^{68}$ Instigação que se teria iniciado em tenra idade do infante, na opinião de A. B. FrEIRE, ob. cit., Vol. II, p. 187.

${ }^{69}$ Segundo uma testemunha dos acontecimentos, o meio-irmão Pedro Afonso - o célebre Conde de Barcelos e igualmente nascido de uma relação ilegítima do monarca -, o infante D. Afonso rebelou-se "por razom que [D. Dinis] queria que reinasse Afonso Sanchez seu filho de barregãa" (Livro de Linhagens do Conde D. Pedro. Portugaliae Monumenta Historica, 7D4, p. 130).

${ }^{70}$ Para uma sequência dos acontecimentos, leia-se, por exemplo, o relato contido em Crónica dos sete primeiros reis de Portugal, Vol. II, edição crítica de Carlos da Silva Tarouca, Lisboa, 1952, pp. 82-96, sobretudo; ou em Crónica de Portugal de 1419, edição crítica com introdução e notas de Adelino de Almeida Calado, Aveiro, 1998, pp. 195-219. E, numa outra perspectiva, A. B. FREIRE, ob. cit., Vol. II, pp. 188-192.
} 
monarca $^{71}$, alicerçada no princípio da soberania como atributo da realeza, afectaram gradualmente a estabilidade nacional, alastrando-se os seus efeitos pelo reino e minando a sociedade, tendo chegado a degenerar em guerra civil, entre 1319 e $1324^{72}$. Não se conhece bem o desenrolar dos acontecimentos, mas parece que, em 1324, D. Afonso Sanches, depois de destituído do cargo de mordomo-mor nesse mesmo ano ou no anterior ${ }^{73}$, foi afastado da corte e de D. Dinis, que morreria no princípio do ano seguinte, ou seja, em 1325. $\mathrm{Na}$ sequência desse afastamento, o bastardo régio terá sido impelido a exilar-se na vila de Albuquerque ${ }^{74}$, no reino de Castela, que passara para o seu domínio em 1304-1306 -uma parte- e em 1308 -a outra parte-, mediante o matrimónio com $\mathrm{D}$. Teresa Martins $^{75}$. E por terras estrangeiras viria a falecer, presumivelmente em meados de

${ }^{71}$ A esse propósito, pode revelar-se esclarecedor o artigo de J. MATTOSO, "A guerra civil de 1319-1324", Portugal medieval. Novas interpretações, pp. 295-298; a ser actualizado pela perspectiva de J. A. de S. M. PIZARRO, "D. Dinis e a nobreza nos finais do século XIII", pp. 91-101.

${ }^{72}$ Sobre essa fase de graves conflitos, constitui uma referência incontornável o citado estudo de J. MAtTOSO, "A guerra civil de 1319-1324", pp. 293-308. As suas reflexões seriam, entretanto, sintetizadas em idem, História de Portugal. A monarquia feudal (10961480), pp. 161-163.

${ }^{73}$ Embora a generalidade dos historiadores aceite o ano de 1324 como a data da destituição e subsequente afastamento de D. Afonso Sanches da corte -talvez na linha do parecer de F. BRANDÃO, $o b$. cit., Parte VI, p. 429-, mais recentemente J. A. de S. M. PIZARRO (Linhagens medievais portuguesas. Genealogias $e$ estratégias (1279-1325), p. 190) divulgou o ano de 1323 como limite máximo documentado para a associação do bastardo à cúria régia.

${ }^{74} \mathrm{E}$ onde estabeleceria, a partir de então, uma corte senhorial, conforme indicação de L. KRUS, A concepção nobiliárquica do espaço ibérico (1280-1380), Lisboa, 1994, p. 254, n. 610.

${ }^{75}$ Sobre a questão, vejam-se o documentado relato de F. BRANDÃO, ob. cit., Parte VI, pp. 146-154; e o actualizado resumo de M. J. BARROCA, ob. cit., pp. 1303-1305, sobretudo.
$1328^{76}$, ao serviço do monarca castelhano, Afonso XI. Em data incerta, o seu corpo foi então levado para o mosteiro que fundou, respeitando-se assim a sua vontade de aí ser sepultado ${ }^{77}$, juntamente com a sua mulher, como ficara expresso na carta de $\operatorname{dotação~}{ }^{78}$.

A criação do cenóbio de Vila do Conde ocorreu cerca de dez anos antes do termo da presença e participação de $\mathrm{D}$. Afonso Sanches na cúria régia, mas foi simultânea da recuperação de um outro convento de Clarissas, situado em Coimbra e, factor mais relevante, patrocinado pela rainha D. Isabel a partir de $1314^{79}$. As tensas relações então existentes entre o casal real, decorrentes sobretudo das altercações geradas em torno do bastardo predilecto e

\footnotetext{
${ }^{76}$ Escreveu Fr. F. da SOLEDADE (ob. cit., pp. 91-92) que foi "muito dificultozo, e totalmente imperceptivel a todas as boas diligencias, que se fizeraõ sobre a materia; porque naõ se acha documento, que mostre com certeza infalivel o anno, em que succedeo a morte de hum e de outro", isto é, tanto de D. Afonso Sanches como de D. Teresa Martins. O falecimento de D. Afonso Sanches, de início apontado para 1329 (idem, ibidem, pp. 92-93), terá ocorrido durante o cerco a Escalona, entre meados de Março e princípios de Agosto desse ano de 1328, de acordo com os dados divulgados por J. ANTUNES, A. R. de Oliveira e J. G. Monteiro, "Conflitos políticos no reino de Portugal entre a Reconquista e a Expansão", Revoltas e Revoluções. Revista de História das Ideias, Vol. 6, Coimbra, 1984, p. 121, n. 35.

${ }^{77}$ Reza a história que D. Afonso Sanches, "depois de faleçer em Castela, se mamdou deytar no Mosteyro da Vyla de Comde, da hordem de Samta Crara, que ele de novo fumdou. E jaz nele sepultado" (Crónica dos sete primeiros reis de Portugal, pp. 143-144).

${ }^{78}$ Vontade registada em várias passagens, como, por exemplo, a propósito das obrigações que os capelães deveriam cumprir, rezando todos os dias nas horas canónicas "no oratorio ou na jgreia do dicto moesteyro despois que nos morrermos ou cada hü̈ de nos $E$ hi formos soterrados digam as duas mjsas que por nos ham de dizer $e$ as oras canonjcas naquelle lugar hu nos Jouuermos soterrados" (Chancelarias portuguesas, p. 136).

79 Ainda que D. Dinis tenha estado envolvido numa fase inicial desse patrocínio, conforme detectou A. P. P. F. SANTOS, ob. cit., pp. 155-176. Veja-se, ainda, F. F. LOPES, ob. cit., pp. 166-192.
} 
do filho legítimo ${ }^{80}$-o futuro rei D. Afonso IV (1325-1357)-, facilmente induziram alguns autores a conjecturar a possibilidade de D. Dinis, com a protecção dispensada ao mosteiro vilacondense, ter manifestado um desejo de rivalizar com a mulher, na sua iniciativa de restaurar a primitiva comunidade conimbricense. Com isso, o monarca lançava a D. Isabel um desafio não limitado ao âmbito religioso, mas equacionado em termos políticos ${ }^{81}$. Um desafio que, na opinião desses mesmos autores, se patentearia até nas dimensões do edifício de Vila do Conde, bem mais avantajadas do que a estrutura da casa clarissa de Coimbra ${ }^{82}$.

A já referida intervenção régia na fundação monástica do primogénito levantou, mesmo, a questão de D. Afonso Sanches ter desempenhado apenas um papel secundário em todo o processo. Com efeito, há quem tenha pensado que, por muita riqueza e poder que possuísse, ele jamais teria a "audácia de afrontar a Rainha e o seu meio irmão" sem o suporte da autoridade máxima, amparando-o e abrindo-lhe caminho ${ }^{83}$. Há até quem tenha considerado D. Dinis o inspirador da criação do cenóbio vilacondense, porquanto a sua forma de actuação, privilegiando-o com todas as doações e isenções atrás

-

${ }^{80}$ Sobre esses conflitos familiares, consultem-se os artigos de idem, "Santa Isabel de Portugal. A larga contenda entre el-rei D. Dinis e seu filho D. Afonso", Colectânea de estudos, 2 a Série, Ano IV, N. o 1, pp. 3-41; e "Santa Isabel na contenda entre D. Dinis e o filho. 13211322", Lusitânia Sacra, T. VIII, Lisboa, 1970, pp. 57-80.

${ }^{81}$ Confira-se em J. P. NEVES, O Mosteiro de Santa Clara de Vila do Conde (Pequena crónica dum grande mosteiro), Vila do Conde, 1982, p. 14.

82 À margem dessa questão específica, e aproveitando o contexto arquitectónico subjacente, sugere-se a leitura de P. DIAS, ob. cit., pp. 43-70; e de C. A. F. de AlmeidA e M. J. BARROCA, ob. cit., pp. 21-33, sobretudo.

${ }^{83}$ Nas palavras de J. P. NeVES, O Mosteiro de Santa Clara de Vila do Conde (Pequena crónica dum grande mosteiro), p. 15. enunciadas, se assemelhava à atitude de quem tomava sobre si a responsabilidade da sua instituição e manutenção, reduzindo o filho a um meio de concretização desse propósito $^{84}$. No entanto, a suposição de D. Afonso Sanches ter funcionado, alguma vez que fosse, como um joguete nas mãos do monarca não transparece na documentação conhecida e analisada. Nem sequer palpita nos actos autógrafos dos fundadores.

Efectivamente, esses manuscritos sobreviventes, consistindo em cartas de venda, doações e ordenações -tipologia documental esta em que se insere a carta de dotação-, levam a acreditar num protagonismo crucial do bastardo régio, não só ao nível da criação do mosteiro de Santa Clara, mas também no quadro dos principais eventos que configuraram o seu percurso de vida. Constituem alguns exemplos a sua participação no governo central, documentada desde $1303^{85}$, e, de forma mais nítida, a sua intervenção na vila de Albuquerque -de que detinha o senhorio-, com a reconstrução da fortificação local nos anos de 1306 e 1314, a sua iniciativa que, apesar das lacunas documentais, melhor se consegue avaliar ${ }^{86}$. No contexto específico da dotação do cenóbio, D. Afonso Sanches expressou-se

${ }^{84}$ Uma circunstância que, na opinião de J. A. FERreIRA ("Villa do Conde. Notas historicas", p. 264), teria até originado um ditado entre as Clarissas de Vila do Conde, segundo as quais "«El-Rei D. Dinis fez o dito mosteiro e seus filhos os infantes de Portugal (D. Affonso Sanches e D. Teresa Martins) o edificaram»".

${ }^{85}$ De acordo com os dados facultados por J. A. de S. M. PIZARRO, Linhagens medievais portuguesas. Genealogias e estratégias (1279-1325) p. 190, n. 146.

${ }^{86} \mathrm{O}$ historiador português que mais se debruçou sobre a actuação de D. Afonso Sanches em Albuquerque foi J. M. C. de SoUSA, que condensaria os resultados das suas pesquisas em "Duas inscrições portuguesas em Espanha (a questão da data das lápidas do castelo de Albuquerque)", O Arqueólogo Português, Nova Série, Vol. II, Lisboa, 1953, pp. 261282. Mais recentemente, a questão foi examinada por M. J. BARROCA, ob. cit., pp. 1296-1313 e 1403-1409. 
sempre de forma assertória, com um discurso pautado pela manifestação da sua categoria social. Procedimento não necessariamente intencional, por ser atributo próprio do seu estatuto, mas retrato fiel de alguém que gozava de poder e autoridade suficientes para levar a cabo os seus desígnios. Alguém que sabia que tinha essas premissas, pelo que sabia também como agir.

Naturalmente, o que se acaba de afirmar aplica-se igualmente a D. Teresa Martins, na medida em que a carta de dotação -quase sempre redigida no plural-, tal como as outras escrituras autógrafas, relacionadas não apenas com o mosteiro de Vila do Conde, foi fruto da vontade do nobre casal ${ }^{87}$. Embora a sua leitura possa, erroneamente, aludir apenas a um universo masculino -talvez consequência da tradição historiográfica ${ }^{88}$-, todas as disposições aí enumeradas e explanadas se apresentam consentâneas com o que se conhece da época em que os fundadores viveram, homens e mulheres que, não obstante as sabidas diferenças, partilhavam um mesmo mundo. Na verdade, o precioso documento encerra informações significativas merecedoras, todas, de maior atenção- para a história portuguesa da religião, da cultura e da arte, das mentalidades e das sensibilidades. Destaquei já alguns aspectos que o manuscrito discriminou. Para além do exemplo, aqui analisado, do empreendimento consistente na criação de um ascetério, bastará acrescentar, creio, o testemunho dado pelos fundadores sobre

87 "E Porem (...) fazemos hü̈ moesteyro de sancta clara no nosso lugar de ujlla de conde E porque nos somos padroeiros do dicto moesteyro assy como aquelles que o fundamos e fizemos no nosso herdamento e pello nosso auer E aa nossa custa qujsemo llo dotar e dar (...) de nossas liures uontades doamos e outorgamos ao dicto nosso moesteyro pera todo sempre e dotamo llo destas cousas que aquj som contheudas" (Chancelarias portuguesas, p. 131).

${ }^{88}$ Por certo iniciada com F. BRANDÃO, ob. cit., Parte VI, pp. 268-270, sobretudo. os conceitos que então imperavam nas práticas de enterramento em espaço sagrado $^{89}$.

$\mathrm{Na}$ generalidade das regulamentações registadas na carta de dotação, mormente as do foro espiritual, o insigne casal não estabelecia cláusulas inéditas, uma vez que também se evidenciavam concordantes com os preceitos e costumes litúrgicos vigentes, como sejam os serviços de capelania ${ }^{90}$ e os sufrágios pelos fundadores e pelo monarca, devidamente reverenciado no documento ${ }^{91}$. No campo da ideologia, indissociável do anterior, o casal também não requeria determinações descabidas para a sua mundividência. Com efeito, a inerente capacidade económica de mandar construir edifícios com funções religiosas, procurando, em simultâneo, consagrar "contra as vicissitudes do tempo e da roda da fortuna"- a supremacia da sua posição social, proporcionava aos elementos da nobreza a desejada proximidade das fontes do poder sagrado e profano ${ }^{92}$. Possibilitando esse eficaz recurso afirmar "a

89 Conceitos que justificariam, assim, certas instâncias do nobre casal. "Outrossy porque a sepultura de dentro das Jgreias nos semelha que nom era se nom pera homens santos ou muy chegados a deus E por nom seerem os nossos moymentos a par dos altares nem tam altos como elles nom nos qujsemos mandar deitar dentro na Jgreia nem poer hi nossos moymentos mais mandamo llos poer hi fora a par da igreia em hüa galilee que hi mandamos fazer pera sepultura de nos e dos do nossa linhagem e dos outros que se hi ouuerem de deitar E porem defendemos que nemhü̈ nom deite dentro na igreia em nemhuü lugar em terra nem em moymento alçado Ca pois nos teemos por razam que a Jgreia e o moesteyro fundamos de nos nom deitar em ella Razom he que hi nom façam os outros que vierem despois como quer que nos afomso sanchez e tareija martjnz esta hordenaçam façamos" (Chancelarias portuguesas, p. 139).

${ }^{90}$ Ibidem, p. 136.

91 "E outra [missa] digam por el rrey dom denjs padre de mim afomso sanchez por conhicimento de mujtas mercees que del recebemos por mujtas uezes" (ibidem, p. 136).

92 Nas palavras de J. MATTOso, "O Românico português. Interpretação económica e social", pp. 165166. 
sua prosápia e poder, muitos fundam mosteiros que tutelavam, para onde destinavam a sua sepultura e os principais sufrágios para a sua alma"93.

Não obstante a sua riqueza informativa, a carta de dotação revelou-se omissa sobre a totalidade das intenções que presidiram à resolução de $\mathrm{D}$. Afonso Sanches e D. Teresa Martins. Para alguns cronistas e autores, os seus motivos seriam, mesmo, considerados «misteriosos» ${ }^{94}$. Lamentavelmente, não se conhecem outros documentos que possam dilucidar a questão. Talvez fosse um empreendimento que, na opinião dos fundadores, não exigisse a composição de outros actos probatórios para a memória colectiva, nem dos coevos nem dos vindouros. Para os hodiernos, esse aparente silêncio daria ensejo a conjecturas e especulações, feliz ou infelizmente, consoante as posturas científicas. Em prol do rigor histórico, não se revela ajuizado proceder a mais extrapolações. Enquanto não se obtiverem resultados decorrentes de uma investigação mais aturada, convirá recordar que qualquer estudo dedicado à figura do bastardo régio, directamente relacionado, ou não, com a criação do cenóbio vilacondense, deve partir de eixos caracterizadores dos elementos da alta nobreza. Elementos para os quais as alianças com mosteiros, traduzidas em fundações, protecções ou simples apoios financeiros, facultariam a "preservação ou acréscimo de poder, quando não a

${ }^{93}$ C. A. F. de AlmeIDA, ob. cit., p. 60. A esse propósito, leia-se M. de L. ROSA, ob. cit., pp. 480-484, sobretudo.

${ }^{94}$ Em Fr. M. da ESPERANÇA, ob. cit., p. 165; e J. A. FERrEIRA, "Villa do Conde. Notas historicas", p. 264. cristalização de uma posição dominante inter pares" ${ }^{195}$.

Porque pertencia a um grupo privilegiado, D. Afonso Sanches situava-se a um nível socioeconómico que conferia automaticamente relevo e prestígio. À semelhança dos seus pares, ele tinha consciência disso. Como se esse estatuto não bastasse, era filho do rei D. Dinis, ainda que ilegítimo, com todas as vantagens, mas também desvantagens, que essa condição comportava. E, de igual modo, ele teria consciência disso, sabendo aproveitar as primeiras e mitigar, quiçá obviar, as segundas. Na sequência das vantagens, angariou riqueza e conquistou poder. E em virtude das desvantagens, impôs respeito e exerceu autoridade. A decisão de fundar o mosteiro de Vila do Conde permite ilustrar uma percepção dessa dualidade, mais ou menos latente na carta de dotação. Por um lado, a iniciativa propiciava a salvaguarda de uma parte dos seus bens, doando-os à instituição religiosa sem abdicar de certos direitos, ou transferindo-os para a gestão do cenóbio após a sua morte e evitando, assim, uma eventual usurpação ${ }^{96}$, mesmo tendo já o casal descendência, na pessoa do seu filho D. João Afonso, sexto senhor de Albuquerque $^{97}$. A par dessa estratégia de prevenção, a presença contínua do monarca

\footnotetext{
${ }^{95}$ M. H. da C. COELHO e R. C. MARTINS, art. cit., p. 482.

${ }^{96}$ Que chegaria a ser tentada pelo seu meio-irmão, assim que subiu ao trono, em 1325. A esse propósito, bem como dos subsequentes acontecimentos, remetese o leitor para A. B. FREIRE, ob. cit., pp. 193-194; e J. Antunes, A. R. de Oliveira e J. G. MONTEIRO, art. cit., pp. 119-121.

97 Sobre o filho do ilustre casal -personagem relevante do reinado de Pedro I de Castela- e respectiva linhagem, vejam-se A. B. FREIRE, ob. cit., Vol. II, pp. 194-199; J. P. NeVES, O Mosteiro de Santa Clara de Vila do Conde (Pequena crónica dum grande mosteiro), pp. 209-210; e, sobretudo para os seus primeiros anos de vida, J. A. de S. M. PIZARRO, Linhagens medievais portuguesas. Genealogias e estratégias (1279-1325), pp. 193-194.
} 
pressupunha uma afirmação política e social. Por outro lado, o caridoso gesto de dois cristãos devotos que, em remissão dos seus pecados, resolveram agradecer a graça de Deus e edificar em Sua honra um lugar santo ${ }^{98}$ proporcionava, ao mesmo tempo, uma forma de ostentar, quiçá infundir, o poder e a autoridade de D. Afonso Sanches.

98 "Porem nos aa honrra de deus e de sua madre sancta maria e de sancta clara em cuja honrra he fundado o dicto moesteyro E em remjmento de nossos pecados" (Chancelarias portuguesas, p. 131). 